\title{
LA INFLUENCIA DE LAS INVESTIGACIONES HISTÓRICO-CULTURALES DEL INSTITUTO WARBURG EN LA KULTURPHILOSOPHIE DE ERNST CASSIRER
}

El historiador del arte Aby Warburg (1866-1929) es uno de los investigadores especializados cuya influencia ha trascendido más, fuera del contexto de su propia disciplina. Su obra no se agota, sin duda, en lo poco que dejó escrito, y no digamos ya en lo que dejó escrito para ser publicado. Y sin embargo, si la obra de este erudito investigador de la cultura renacentista ha alcanzado otros múltiples y diversos ámbitos del saber, casi todos ellos relacionados con los estudios históricos y culturales en línea con la tradición burkhardtiana, ello se debe a que Warburg fue un investigador con un legado intelectual y una metodología propios. Un «mensaje» profundo y humano, de no fácil lectura e interpretación en sus propios textos, pero un mensaje que cobró forma alrededor de su biblioteca y del círculo de intelectuales que congregó entorno a ella. Una biblioteca erudita, consagrada a la memoria histórica, que encarna el mensaje de Warburg para la posteridad: su fe inquebrantable en la eficacia de la «Kulturwissenschaft».

\section{Warburg y el estudio de la Antigüedad Clásica}

Aby Warburg estudió historia del arte en Bonn, Florencia y Estrasburgo. Se especializó en el renacimiento artístico florentino, un período de gran interés para tantos otros historiadores y culturalistas. Sin embargo, acaso por su temperamento y su carácter personal, Warburg fue un historiador del arte atípico. Intelectual introvertido, enfermizo, con un mensaje oracular, rehuyó siempre la docencia universitaria para dedicarse al estudio guiado por sus propios intereses intelectuales. Su peculiar sensibilidad estética se conformó en la confluencia de ciertos acontecimientos que marcaron decisivamente su vida y su personalidad, y algunos motivos estéticos problemáticos que le persiguieron durante todo su complejo itinerario intelectual. A Warburg le preocuparon problemas estético-culturales de la civilización renacentista, que abordó de una forma muy personal y original desde el enfoque de la «psicología de la cultura».

Hombre de una profunda erudición en el fecundo fin de siècle florentino de la época de Lorenzo de Medici, Warburg estudió los motivos artísticos del «movimiento intensificado» y la simbología astral en las representaciones pictóricas renacentistas de la mitología clásica (en Miguel Ángel, Leonardo, Botticelli, Lippi, Masaccio, Durero, ...). Distanciándose del problema de la evolución autónoma de las formas en que se situaban los historiadores de los estilos, el estudioso hamburgués centró su consideración más en la perspectiva del «encuentro» de fuerzas culturales, como clave explicativa de un período que se constituía, ya desde el siglo XVIII, en piedra de toque de las diferentes posturas respecto a la historiografía de los estilos, e incluso, más allá, en piedra de toque de las diferentes posturas estético-ideológicas generales.

Sin renunciar a una concepción nietzscheana de la antigüedad como polaridad entre aspectos dionisíacos y aspectos apolíneos, Warburg suavizó su concepción inicial —más radical— del Renacimiento como «des-encuentro», como conflicto entre energías dinámicas opuestas, como progreso dialéctico del «triunfo» de lo clásico, hacia una concepción -más ponderada - del Renacimiento como resolución fecunda de una neutralización y armonización psicológica, de una «compatibilización»-concepto que toma de Spencer- de tendencias culturales contrapuestas: lo nuevo y lo viejo, lo pagano y lo religioso. 
La intensidad del arte del primer Renacimiento florentino se hace ininteligible si se prescinde de la resistencia a un realismo nórdico alla franceze —el realismo flamenco- que dominó en la primera mitad del siglo XV el gótico internacional, y al que un gran estilo idealizante all'antica tuvo que vencer. El realismo gótico, por tanto, como «impedimento», como resistencia, pero también, lo gótico como catalizador, como precipitante, como «aliado».

El espíritu revisionista que caracterizó la visión de Warburg sobre la historia del arte, queda ejemplarizado en esta sentencia escrita al final de su vida:

«Erst wenn die Kunstgeschichte zeigen wird ... dass sie das Kunstwerk in einigen Dimensionen mehr sieht als bisher, wird sich das wissenchaftliche und allgemeine Interese unsere Tätigkeit wieder mehr zuwenden» ${ }^{1}$.

\section{El interés warburguiano por la Kulturwissenschaft}

Aby Warburg nació en Hamburgo el 13 de junio de 1866 en el seno de una familia judía conservadora, como Adolph Goldschmidt (1863-1944) y Max J. Friedländer (1867-1958), los más famosos historiadores del arte alemanes. Por ser hijo del banquero Moritz Warburg, Aby parecía abocado al mundo de las finanzas, como algunos de sus hermanos, destacados financieros y economistas, si no fuera por una temprana y profunda preocupación por el arte. A este respecto hay dos hechos biográficos muy significativos: en sus delirios por las fiebres tifoideas de 1873, siendo un niño, confiesa que veía reproducidas las grotescas ilustraciones de las Petites misères de la vie conjugale de Balzac, y luego, ya en plena adolescencia, le vendió a su hermano Max (de doce años) los derechos de primogenitura sobre el patrimonio familiar a cambio de que le comprara todos los libros que deseara durante toda su vida. Estas anécdotas, infantiles ciertamente, cobran quizá su plena significación cuando se contextualizan en el complejo itinerario intelectual warburgiano, reflejado en la inmensa tarea de recopilación bibliográfica de su vida, y en la evolución de lo que empezó siendo su modesta biblioteca personal, que pasará luego a ser la Kulturwissenschaftliche Bibliothek Warburg en Hamburgo y, finalmente, desde 1944 y hasta la actualidad, el Warburg Institute de la Universidad de Londres, del que se hizo cargo el gobierno británico al constatar que un 30\% de sus fondos bibliográficos no figuraban en la Biblioteca del British Museum.

Dentro de la orientación genérica a la que circunscribió su actividad investigadora el Instituto, el ámbito de problemas de la Kulturwissenschaft, el fundador se dedicó con predilección al tema de lo que denominó «das Nachleben der Antike», la pervivencia o el carácter redivivo de la antigüedad clásica, es decir, la influencia de la antigüedad en la civilización europea moderna, en todos los aspectos: sociales, políticos, religiosos, científicos, filosóficos, literarios, artísticos, ... Warburg se dedicaba como él mismo decía, a la «vida futura» de la antigüedad clásica, o como afirma coloquialmente en una carta a su amigo —el historiador del arte belga- Jacques Mesnil, «que représentait en réalité l'antiquité pour les hommes de la Renaissance».

\section{La reevaluación del Mundo Clásico}

El culto, heredado del siglo XVIII, que la concepción tradicional mostraba hacia el fin de siècle renacentista, que transformaba el Quattrocento florentino en una utópica edad de oro,

1 «Hasta que la historia del arte no demuestre ... que ve la obra de arte en más dimensiones de lo que la ha visto hasta ahora nuestra actividad, no atraerá de nuevo el interés de los estudiosos y del público en general». (Carta a Mesnil, 28 de agosto de 1927). 
como feliz y fácil despertar emancipatorio de las pesadillas del dogmatismo medieval, chocó con la sensibilidad estética de un Warburg para el que toda emancipación había de ser dolorosa, como su propia emancipación de las prácticas familiares de la ortodoxia judía. Probablemente el más profundo leit-motiv de su vocación estética residiese en esta radical insatisfacción con la interpretación tradicional del Renacimiento que tuvo que estudiar en su juventud.

También la lectura del Laocoonte de Lessing, realizada junto a su profesor Oscar Ohlendorff, le marcó profundamente y le llevó a cuestiones abstractas tales como la naturaleza de la imagen visual y su función dentro de la jerarquía de los signos, así como al problema de la expresión del sufrimiento, del comedimiento y del abandono en estados emocionales extremos, problema del exceso emocional que los antiguos llamaron «parenthyrsus». Un pathos extremo que no podía resultar válido en las artes visuales, precisamente porque el signo visual es estático y sólo puede insinuar el movimiento. Si abandonan este comedimiento o moderación, la pintura y la escultura transgreden su propio ámbito creativo, que es el de la belleza visual.

Desde su lectura de la estética de Lessing, Warburg se replanteó —en sus estudios sobre diversos géneros de documentos visuales de la antigüedad clásica - el problema del pathos del «movimiento intensificado» frente a un pathos de lo desmedido, aunque siempre consideró la tendencia al movimiento incontenido y a la gesticulación apasionada y violenta, que en la imagen se intenta refrenar, como una muestra de debilidad más que de fuerza expresiva, como una prueba manifiesta de decadencia moral. Tales teorizaciones, así como sus pormenorizados estudios en obras pictóricas como las de Botticelli, especialmente en las alegorías mitológicas del Nacimiento de Venus y la Primavera, y en los sarcófagos y relieves neoáticos, hicieron que su profunda reinterpretación en términos conflictivos del pathos renacentista no se pudiera agotar — sin más— en el propio carácter conflictivo de su textura mental.

Con su revisión del Quattrocento florentino Warburg participó de esa reevaluación del mundo clásico de finales del siglo XIX, que deconstruyó críticamente esa imagen onírica e idealizada de una Grecia Antigua como paraíso soñado de deseos cumplidos, heredada de los clásicos alemanes (Winckelmann, Goethe, Schiller, ...), y desde la que se envidiaba el vivir de un griego idealizado que no conocía los conflictos internos del alma introducidos por el cristianismo. La rigurosa investigación histórica y antropológico-etnográfica, así como los estudios de Bachofen (religión griega), Burckhardt (psicología griega), Nietzsche (tragedia) o Hermann Usener (mitología griega) - maestro de Warburg en Bonn-, y en el ámbito anglosajón, las obras de Jane Harrison (civilización griega), Gilbert Murray (literatura y religión griega), incluso La rama dorada de Frazer, fueron desmoronando progresivamente, al tiempo que reajustando, esa idealizada visión de la antigüedad clásica.

\section{El legado de Warburg: la Bilioteca y sus herederos}

La publicación de las Obras Completas de Warburg fue un proceso trastabillado y complicado. Lo inició su discípulo y sucesor al frente del Instituto, Fritz Saxl (1890-1948), tras la muerte del fundador en Hamburgo en octubre de 1929. Sin embargo, de la voluminosa obra proyectada, sólo vieron la luz los dos primeros volúmenes, publicados en Alemania en 1932 con el título de Gesammelte Schriften. Die Erneuerung der heidnischen Antike ${ }^{2}$. Los escritos

\footnotetext{
2 Warburg, Aby: Gessamelte Schriften. Die Erneuerung der Heidnischen Antike, «The Warburg Institute»,
} 1932. 
recogidos en las Obras Completas fueron recopilados, completados con minuciosidad y editados por la ayudante personal de Warburg, Gertrud Bing, asistida por F. Rougemont.

Los avatares y constantes interrupciones que sufrió el proyecto de publicación de las obras de Warburg, tuvieron mucho que ver con la convulsa coyuntura socio-política alemana de la época, con el ascenso de Hitler al poder y con la intolerancia del nacional-socialismo hacia cualquier iniciativa cultural independiente. Unas circunstancias adversas que, en 1933, forzaron a la emigración de la Biblioteca y de los intelectuales a Londres. Gracias al apoyo de Lord Lee of Fareham, de Samuel Courtauld y de la propia familia Warburg, la Bibliothek Warburg se instaló primero en Thames House, en 1934, y en el Imperial Institute, en 1937, hasta que ya en 1944 se incorporó definitivamente a la Universidad de Londres ${ }^{3}$.

En la Inglaterra prebélica y bélica, ni Saxl, primero, ni Bing, después, pudieron completar los planes editoriales de los Gesammelte Schriften, hasta que Gombrich, un nuevo colaborador para la edición de la gran sinopsis visual del mensaje warburgiano que sería el «Atlas» ilustrado titulado Mnemosyne, acabara con el tiempo encargándose del proyecto.

Introduciéndose en el universo warburgiano, Gombrich, se percató de la dificultad que entrañaba el proyecto original de publicación del disperso, y con frecuencia oscuro, legado literario de Warburg. Un legado que, en su dificultad para escribir y publicar, para encontrar una forma definitiva más allá de todas las posibilidades caleidoscópicas de expresión y redacción, el erudito hamburgués, la mayor parte de las veces, sólo esbozaba en borradores, anotaciones con diversos intentos de formulación, escritos con abundancia de fragmentos inconclusos con un estilo personalísimo, probablemente influido por Thomas Carlyle ${ }^{4}$. Tales dificultades llevaron a Gombrich a la convicción de que la propia obra de Warburg exigía no limitarse a publicar las notas inéditas escuetamente, sino más bien utilizarlas en una exposición contextualizada de sus ideas. Lo que hizo en su biografía sobre Warburg:

«(La biografía intelectual de Aby Warburg). Es una biografía intelectual, no psicológica; me interesaba por sus ideas y sus interpretaciones, más que por sus problemas psicológicos, pero encontré que ambos aspectos no podían separarse. El propio Warburg lo sabía muy bien; lo reconoció pronto al comprobar que su interpretación de los banqueros florentinos del círculo de Lorenzo de Médicis estaba influida por su propia experiencia con los banqueros de Hamburgo y, naturalmente, por su actitud ambivalente hacia su propio medio. Cerca del fin de su vida, escribió aquella asombrosa nota sugiriendo que a veces le parecía que su interpretación de la tradición clásica y sus polaridades se apoyaba en lo que llamó un "reflejo autobiográfico", debido a su constitución maníaco-depresiva;

3 Sobre la etapa de la Biblioteca en Alemania (1919-1933) véase la tesis doctoral de Carl Hollis Landauer, de la Universidad de Yale (Mayo de 1984), titulada The survival of antiquity: The german years of the Warburg Institute, U.M.I. Dissertation Information Service, Ann Arbor, 1988. Contiene cuatro capítulos dedicados a los principales warburguianos (el fundador, Saxl, Cassirer y Panofsky) en su relación con la Biblioteca.

Gombrich sostiene esta opinión, aunque otro ilustre warburguiano, Edgar Wind, discrepa de que esta influencia se pueda considerar de forma seria. A Warburg le interesaba del Sartor Resartus de Carlyle su «filosofía del vestido», y sus observaciones sobre la naturaleza de los símbolos en el vestir. Pero Warburg nunca intentó, según Wind, imitar el estilo de los bruscos manierismos germánicos del lenguaje de Carlyle. También discrepa Wind del valor que Gombrich atribuye a los papeles y borradores de Warburg. En realidad, para el primer ocupante de la cátedra de Historia del Arte en la Universidad de Oxford y discípulo directo de Warburg, la «visión desde dentro» que presenta Gombrich sobre Warburg no es necesariamente la más auténtica. Ni en su carácter personal, caracterizado por «das bewegte Leben», para Wind, ni en el peso que poseen determinadas concepciones teóricas, el «Warburg» de Gombrich es el correcto según Wind. En lo teórico, Wind destaca la importancia que tiene en el pensamiento de Warburg el concepto de la Einfühlung (empatía), introducida en psicología y en estética por Robert Vischer en su tratado Über das optische Formgefühl de 1873. Sobre estas discrepancias véase el libro de Wind, La elocuencia de los símbolos. Estudios sobre arte humanista (Alianza Forma, Madrid, 1993) y, sobre la relación Warburg-Wind, véase el examen detallado de sus encuentros en Buschendorf «"War ein sehr tüchtiges gegenseitiges Fördern”: Edgar Wind und Aby Warburg», IDEA, IV, 1985, pp. 165-209. 
el elemento maníaco estaba representado por figuras en rápido movimiento, como el tipo al que llamaba la "ninfa", y el elemento depresivo por el dios del río recostado.» ${ }^{5}$

En esta obra ${ }^{6}$, Gombrich llevó a cabo la contextualización que precisaba el complejo pensamiento de Warburg, acompañando además los textos traducidos y escasamente retocados, con los originales alemanes, e incluyendo 65 láminas ilustrativas, así como la interesante e inédita memoria de Saxl, escrita en 1943, sobre la historia de la Kulturwissenschaftliche Bibliothek Warburg de Hamburgo.

Es la conocida biblioteca warburguiana en la que se refugiaron intelectuales como el Dr. R. Klibansky, que horrorizado por la situación en Heidelberg, propuso crear un centro de estudios fuera de Alemania donde continuar la tradición del humanismo alemán, y en cuya órbita estuvieron figuras tan relevantes y de campos tan diversos como el ya citado Fritz Saxl (historia del arte y de la religión), G. Pauli, Erwin Panofsky o Edgar Wind (historia del arte), K. Reinhardt (lenguas clásicas), R. Salomon (historia bizantina), H. Ritter (lenguas orientales), o el mismísimo Ernst Cassirer (filosofía y teoría de la cultura) ${ }^{7}$, así como, temporalmente, diversos eruditos e investigadores extranjeros.

La Biblioteca constituyó un círculo erudito de investigación multidisciplinar, fundamentalmente de tipo histórico-culturalista, donde confluían estudios de disclipinas diversas, y donde abundaban los estudios de estética, de las formas artísticas y religiosas, de iconología e iconografía, estudios de historia del arte, de la literatura, de las concepciones y representaciones mitológicas, simbólicas, etc.

\section{La influencia warburguiana en la Kulturphilosophie de Cassirer}

La decisiva ampliación del horizonte epistemológico que Cassirer fundamenta y desarrolla en profundidad en su filosofía post-marburguiana ${ }^{8}$, fue intuido con claridad por el filósofo a

5 Gombrich, Ernst H.: Temas de Nuestro Tiempo. Propuestas del siglo XX acerca del saber y del arte, Debate, Madrid, 1997, p. 51.

6 En la biografía titulada Aby Warburg. Am intellectual Biography. With a Memoir on the History of the Library by Fritz Saxl, «The Warburg Institute», 1970. Segunda edición en Phaidon Press and University of Chicago Press, 1986. Traducción castellana Aby Warburg. Una biografía intelectual, Alianza Editorial, Madrid, 1992.

7 En el fondo de publicaciones del Warburg Institute figuran varios trabajos de Cassirer, publicados como Studien y Vorträge der Bibliothek Warburg en los años 20 cuando estaba de profesor en Hamburgo: así, Der Begriff der symbolischen Form im Aufbau der Geisteswissenschaften (1921-22), Die Begriffsform im mythischen Denken (1922), Sprache und Mythos. Ein Beitrag zum Problem der Götternamen (1925), Individuum und Kosmos in der Philosophie der Renaissance (1927), Die platonische Renaissance in England und die Schule von Cambridge (1932). Y precisamente sobre Cassirer, escribió Warburg, un año antes de su muerte en 1929, un artículo titulado «Ernst Cassirer. Warum Hamburg den Philosophen Cassirer nicht verlieren darf», que se publicó en el número 173 del Hamburger Fremdenblatt, con fecha 23 de junio de 1928, y que no está recogido en los Gesammelte Schriften. Recientemente se ha traducido al español, casi veinticinco años después del original, la obra de otro ilustre warburguiano muy influido por Cassirer, me refiero a Michael Baxandall y su primer libro Giotto and the orators. (Giotto y los oradores, La Balsa de la Medusa, Visor, 1996). Un libro dedicado al inmenso esfuerzo por recuperar el latín clásico, sobre todo ciceroniano, que llevaron a cabo los humanistas desde mediados del siglo XIV, tras los siglos de corrupción del culto idioma a causa de las contaminaciones de las lenguas vernáculas y los barbarismos del latín que empleaba la escolástica. El latín clásico constituía para los humanistas un instrumento flexible y preciso para hablar y considerar las obras de arte, todo un género desde la Antigüedad, pero, además, toda una estructura mental o un marco de referencia, que constituye los orígenes remotos de la crítica de arte moderna.

${ }^{8} \mathrm{Si}$ es que se puede hablar de una etapa post-marburguiana, puesto que, aunque de hecho se hace, el propio Cassirer insiste en que su filosofía simbólica, no sólo no rompe con la epistemología marburguiana, sino que es un desarrollo, original, de la misma. Es lo que Cassirer intentó explicar a Heidegger en Davos. (Disputaciones davosianas). 
raíz de su contacto con la «Kulturwissenschaftliche Bibliothek Warburg» en Hamburgo. Cassirer que cree necesario extender la reflexión crítica a un nuevo horizonte epistemológico, que ya no es exclusivamente el de las ciencias físico-matemáticas de la experiencia, intentará elaborar una fundamentación o justificación epistémica de las Geisteswissenschaften o ciencias del espíritu y de las Kulturwissenschaften o ciencias de la cultura, conjunto de ciencias a las que Ortega propuso denominar sencillamente Humanidades.

En su encuentro con las investigaciones culturales multidisciplinares de la Bibliothek Warburg, hacia 1920, Cassirer concibe el proyecto de desarrollar una reflexión filosófica sobre la función simbolizadora, como función epistémica general que conecta las formas fundamentales del saber y de la cultura; inicio de la constitución de su filosofía última y más original.

La Biblioteca warburguiana es una institución privada, en esta época, consagrada a «Mnemosyne», a la memoria histórica y cultural, dedicada al estudio de un ámbito genérico de problemas al que los alemanes denominan «Kulturwissenschaft», un ámbito de investigación difícil de precisar y que no posee una traducción exacta a nuestra lengua ${ }^{9}$.

En su primera toma de contacto, Cassirer no sintonizó con la orientación histórico-culturalista de las investigaciones de la institución warburguiana, por lo que inicialmente se distanció de ella. Este hecho es comprensible teniendo en cuenta la orientación cientificista del neokantismo marburguiano en la que se había formado y que él mismo encabezaba junto a los fundadores Cohen y Natorp.

Unos cinco años después de conocer a Warburg y refiriéndose a la impresiones de aquel primer encuentro, Cassirer escribió:

«En la primera conversación que tuve con él, Warburg observó que los demonios, cuyo dominio en la historia de la humanidad había intentado explorar, se habían vengado apoderándose de él» ${ }^{10}$.

No obstante, Cassirer volvió, y fue en el reencuentro con la institución de Warburg en Hamburgo, donde el filósofo de Breslau concibió por vez primera su proyecto de reflexión filosófica sobre las «symbolische Formen», sobre las diversas —incluso divergentes- orientaciones epistémicas simbólicas que articulan la totalidad del saber y conforman la cultura.

La relación de la Bibliothek Warburg con el proyecto cassireano de una «Philosophie der symbolischen Formen», especialmente en sus inicios, en su concepción fundamental y en sus primeras formulaciones, se pone de manifesto en una serie de trabajos iniciales, preliminares, publicados originariamente como Studien y Vorträge de la Biblioteca a principios de los años 20, y que fueron recogidos posteriormente en un libro titulado Wesen und Wirkung des Symbolbegriffs ${ }^{11}$.

9 Véase el capítulo «El concepto de Kulturwissenschaft en Warburg y su importancia para la estética» en Edgar Wind, La elocuencia de los símbolos. Estudios sobre arte humanista, Alianza Editorial, Madrid, 1993.

Sobre el significado del término «Kulturwissenschaft» y la dificultad de su traducción, véase la introducción de Edgar Wind a la edición inglesa de A Bibliography on the Survival of the Classics, I (1934), pp. 5 y ss. Para Wind, el trasfondo del interés de Warburg por la Kulturwissenschaft debe buscarse en los escritos de Windelband, Rickert y Dilthey de finales del siglo XIX sobre la relación entre historia y ciencias naturales.

10 De la alocución de Cassirer en el funeral de Warburg en Aby M. Warburg zum Gedächtnis (edición privada, Darmstadt, 1929). Tomado de Edgar Wind, La elocuencia de los símbolos. Estudios sobre arte humanista, Alianza Editorial, Madrid, 1993, p. 165.

Sobre la relación Warburg-Cassirer véase además p. 164.

También Landauer, C. H., en op. cit., dedica el capítulo III a la relación de Cassirer con la Biblioteca Warburg.

11 La obra Wesen und Wirkung des Symbolsbegriffs, (Wissenschaftliche Buchgesellschaft, Darmstadt, 1994, edición microfilmada de la 1. edición de 1956) se compone de cuatro trabajos: Die Begriffsform im mytischen Denken 
Según su discípulo Edgar Wind, la contribución más decisiva de Warburg al método histórico fue «concebir las humanidades no sólo en su especificidad y en su totalidad, sino sobre todo en su interrelación» ${ }^{12}$.

En Der Begriff der symbolischen Form im Aufbau der Geisteswissenschaften, Cassirer expone al círculo de intelectuales de la Biblioteca, lo que más le impresionó de las investigaciones multidisciplinares que allí se desarrollaban, y que no estriba tanto en los contenidos específicos de esas investigaciones, cuanto en el «principio de estructuración», al que todas ellas se encontraban referidas.

«Era obvio, en efecto, que las historias del arte, de la religión, del mito, del lenguaje y de la cultura no se hallaban dispuestas simplemente una al lado de la otra, sino que estaban manifiestamente relacionadas entre sí y referidas, todas ellas, a un centro ideal común. (...) Sin duda, esta relación misma parece ser a primera vista de carácter puramente histórico.» ${ }^{13}$

Y sin embargo, la relación entre estas disciplinas no se agota en la dimensión de la consideración meramente histórica en la que trabajan preferentemente los warburgianos.

Los especialistas respectivos de cada uno de estos campos perciben una conexión formal, una «Formeinheit» que los conecta, en la medida en que esos especialistas son capaces de distanciarse del restringido dominio de objetos que constituye su campo específico de estudio.

Cassirer contempla ya los diferentes ámbitos epistémicos de comprensión cultural y expresión humana desde una dimensión común, los piensa como «symbolische Formen», esto es, como «formas» $\mathrm{o}$ «funciones» simbólicas generales.

En su obra posterior sobre las Kulturwissenschaften, Cassirer se refirió a las fórmulas emotivas del pathos, la gran aportación de Warburg a la historia del arte, dentro del problema general del lenguaje de las formas artísticas. Para el filósofo de Breslau estas soluciones no sólo enriquecen la historia del arte desde el punto de vista de sus contenidos, sino que, además, suponen una innovación metodológica en la forma de investigar la historia del arte. En realidad, Cassirer considera que en sus investigaciones sobre la cultura renacentista, Warburg se encontró con «un problema fundamental y sistemático de toda ciencia de la cultura» ${ }^{14}$ : El hecho de que toda forma artística y cultural, para resultar comunicativa, tiene que poseer cierta consistencia y estabilidad interior, pero a la vez ha de constituir formas mudables, esto es, cierta capacidad de cambio.

«(...) Todo empleo de las formas entraña yạ, por el simple hecho de operarse en diversos individuos, una cierta modificación sin la cual sería inconcebible» ${ }^{15}$.

(Studien der Bibliothek Warburg 1, 1922), Sprache und Mythos. -Ein Beitrag zum Problem der Göternamen Personen-und Sachverzeichnis (Studien der Bibliothek Warburg 6, 1925), Der Begriff der symbolischen Form im Aufbau der Geisteswissenschaften (Vorträge der Bibliothek Warburg, 1921-1922), y, un último y muy posterior trabajo, Zur Logik des Symbolbegriffs (Theoria, Göteborg 2, 1938) en que Cassirer responde a las objeciones del filósofo sueco — de la (nueva) Escuela de Uppsala-Konrad Marc-Wogau a su Philosophie der symbolischen Formen.

Hay traducción al castellano con el título Esencia y efecto del concepto de símbolo (F.C.E., México D.F., 1975), traducción de Carlos Gerhard.

${ }_{12}$ Wind, Edgar, op. cit., nota en p. 63.

13 El concepto de la forma simbólica en la construcción de las ciencias del espíritu, en Esencia y efecto del concepto de símbolo, F.C.E., México D.F., 1975, p. 159.

${ }_{14}$ Cassirer, Ernst: Las Ciencias de la Cultura, 1. e․ esp., traducción de Zur Logik der Kulturwissenschaften (1942). F.C.E., México D.F., 1951, p. 176.

15 Ibidem. 
La cultura es el resultado de una tensión entre tendencias antagónicas, un equilibrio siempre inestable entre las fuerzas que tienden a la conservación de las formas y las que tienden a la renovación. Es el proceso estructurador interno de la cultura, un drama perpetuo, que no se resuelve necesariamente en tragedia. Cassirer se aproxima así a la concepción nietzscheana de la cultura de Warburg.

«La obra (artística, cultural) no es, en el fondo, otra cosa que un hecho humano condensado, cristalizado como ser, pero que tampoco en esta cristalización reniega de su origen. La voluntad creadora y la fuerza creadora de que emanó perviven y perduran en ella, inspirando nuevas y nuevas creaciones.» ${ }^{16}$

JUAN M. ${ }^{\underline{a}}$ DíEZ SANZ

\section{NUEVA OBRA DEL MAESTRO DE ASTORGA}

Se encuentra en comercio ${ }^{1}$, procedente de una colección italiana, una tabla cuyo tema es Jesús entre los doctores; figura en catálogo como perteneciente a la escuela de Juan de Borgoña, pero ha de incluirse entre la obra del Maestro de Astorga. La personalidad artística de este pintor anónimo de la primera mitad del siglo XVI fue trazada por Angulo ${ }^{2}$ y Post $^{3}$, y en los últimos años, el catálogo de su obra se ha visto incrementado sobre todo por las atribuciones hechas por Díaz Padrón ${ }^{4}$.

El Maestro de Astorga trabajó principalmente por tierras leonesas, de ahí su denominación, aunque su radio de acción se extiende por otras provincias castellano-leonesas, sobre todo por Zamora y Palencia; en esta última sitúa Angulo su formación ${ }^{5}$, lo que se evidencia en la dependencia que tiene de las obras de Juan de Flandes y Pedro Berruguete, aunque a partir de los tipos y composiciones de estos dos pintores, el Maestro de Astorga presenta un lenguaje más evolucionado e italianizante, que Post ${ }^{6}$ atribuye a la influencia de Juan de Borgoña. Pese a que sí se observa cierta dependencia de Borgoña, nuestro pintor se encuentra más próximo a la Escuela Umbra del Quattrocento, en especial es deudor de los delicados paisajes y de la diafanidad espacial de Perugino.

El conjunto de la obra atribuída a este maestro a partir del retablo de la Pasión de la catedral de Astorga, fechado en 1530, es una amalgama en la que de momento no es posible determinar los límites entre la obra personal del maestro y la de sus colaboradores. Uno de los asuntos más problemáticos es su actuación en Zamora, donde destaca un pintor de su círculo denominado Maestro de Zamora que algunos identifican con Juan Rodríguez de Solís; en la tabla del Cristo entronizado en el trascoro de la catedral zamorana, atribuida a este artista, ha-

${ }^{16}$ Op. cit., p. 191.

Finarte. Milán. 28-abril-1998. Galería Asta, n.․o 1039.

Angulo Íñiguez, Diego: «El Maestro de Astorga», Archivo Español de Arte, t. 16, 1943, pp. 404-409; «Varios pintores de Palencia. El Maestro de Astorga», Archivo Español de Arte, t. 18, 1945, pp. 229-232; La pintura del Renacimiento, Ars Hispaniae, t. XII, Madrid, 1953, pp. 106-109.

3 Post, R. Ch.: A history of Spanish Painting, t. IX, 2, Cambrigde, Mass., 1947, pp. 550-570.

4 Díaz Padrón, M. y Padrón Mérida, A.: «Miscelánea de pintura espaglola del siglo XVI», Archivo Español de Arte, t. 56, 1983, pp. 193-219; Díaz Padrón, M. y Seguí, M.: «El Maestro de Astorga: nuevas tablas inéditas o poco conocidas en colecciones españolas y extranjeras», Archivo Español de Arte, t. 62, 1989, pp. 345-354.

5 Angulo, D.: «Varios pintores de Palencia. El Maestro de Astorga», Archivo Español de Arte, t. 18, 1945, p. 231.

6 Post, R. Ch., Op. cit., pp. 550-551. 